\title{
LESÕES CUTÂNEAS TIPO TUMORAIS ASSOCIADAS À INFEÇÃO POR AVIPOXVIRUS EM UMA MARRECA-CABOCLA (Dendrocygna autumnalis)
}

\author{
Washington Luiz AsSunção Pereira ${ }^{1}$, Áurea Linhares Martins GabrieL ${ }^{2}$, SUEllen da Gama

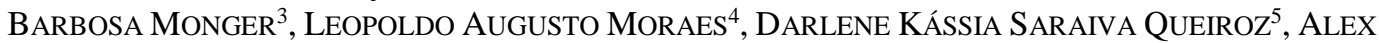 \\ JUNIOR SOUZA DE SOUZA ${ }^{6}$ \\ ${ }^{1}$ Professor Doutor da Universidade Federal Rural da Amazônia, Belém, PA, Brasil.wkarton@terra.com.br \\ ${ }^{2}$ Pós-Graduanda da Universidade Federal do Pará \\ ${ }^{3}$ Professora Mestre da Universidade Federal Rural da Amazônia, Belém, PA, Brasil. \\ ${ }^{4}$ Pós-Graduando da Universidade Federal do Pará \\ ${ }^{5}$ Pós-Graduanda da Universidade Federal Rural da Amazônia \\ ${ }^{6}$ Pós-Graduando da Universidade de São Paulo, São Paulo, SP, Brasil.
}

\begin{abstract}
O setor de reabilitação de aves selvagens do Parque Mangual das Garças, localizado em Belém, Pará, recebeu um espécime de Marreca-cabocla (Dendrocygna autumnalis). $\mathrm{O}$ animal apresentava lesões nodulares em regiões desprovidas de penas na asa, que consistiam de dois grandes nódulos cutâneos de aspecto tumoral, que mediram $4,2 \times 3,8 \mathrm{~cm}$ e $2,8 \times 2,2 \mathrm{~cm}$ de comprimento e largura, respectivamente. Os nódulos foram removidos cirurgicamente, fixados em formol a $10 \%$, e as amostras foram processadas para histopatologia, coradas pela
\end{abstract}

hematoxilina-eosina. $\mathrm{Na}$ análise histopatológica, observaram-se acantose e expressiva hiperceratose; várias células mostraram espongiose. O diagnóstico da bouba foi estabelecido pelo sinal patognomônico da presença de grandes corpúsculos de inclusão eosinofílicos intracitoplasmáticos (corpúsculos de Bollinger) nas células epiteliais da lesão tumoral. Este é o primeiro relato de infecção por poxvírus em ave selvagen no Estado do Pará, Brasil.

PALAVRAS-CHAVE: aves selvagens; Avipoxvirus; bouba aviária; doença viral.

\section{CUTANEOUS TUMOR-LIKE LESIONS ASSOCIATED WITH INFECTION BY AVIPOXVIRUS IN A Dendrocygna Autumnalis}

\section{ABSTRACT}

The fowlpox, also known as contagiosum epithelioma, is caused by a poxvirus of the genus Avipoxvirus and affects both domestic and wild birds. The disease has two forms cutaneous and diphtheria. In March 2008 the sector of rehabilitation of wild birds from Mangual das Garças Park, located in Belém, Pará attended a duck (Dendrocygna autumnalis) that had nodular lesions in regions of the wing devoid of feathers. The lesions consisted of two large cutaneous tumor-like nodules that measured $4,2 \times 3,8 \mathrm{~cm}$ and $2,8 \times 2,2 \mathrm{~cm}$ in length and width, respectively. The nodules were surgically removed, fixed in $10 \%$ formalin, processed and stained with hematoxylin-eosin. Histopathology showed acanthosis and expressive hyperkeratosis, some cells showed spongiosis. The confirmatory diagnosis of fowlpox was established by the pathognomonic sign of the presence of large intracytoplasmic eosinophilic inclusion corpuscles (Bollinger bodies) in epithelial cells. This is the first report of poxvirus infection in a wild bird in the State of Pará, Brazil.

KEYWORDS: Avipoxvirus; fowlpox; viral disease; wild bird. 


\section{INTRODUÇÃO}

A bouba aviária ou varíola aviária é uma das enfermidades de aves mais comuns e afeta tanto espécies domésticas como silvestres ${ }^{1}$. É causada por um vírus DNA envelopado da família Poxviridae, gênero Avipoxvirus (AVP), de acordo com a classificação do Comitê Internacional de Taxonomia de Vírus - ICTV. A doença é de notificação obrigatória pela Organização Mundial de Saúde Animal (OIE), já que é uma moléstia altamente contagiosa e está disseminada em todo o mundo, podendo atingir aves de qualquer idade, apesar de ser mais comum e grave nas jovens ${ }^{2}$.

O AVP pode infectar aves de todas as raças, tendo sido descrito em mais de 232 espécies em 23 ordens de aves ${ }^{3}$. A doença tem duas formas, a cutânea e a diftérica ${ }^{4}$; entretanto, animais infectados podem apresentar os dois tipos da doença simultaneamente ${ }^{5}$ ou até mesmo formas incomuns de lesões ${ }^{6,}$. A forma cutânea, mais conhecida como bouba aviária, é a mais comum e acomete principalmente os passeriformes. As lesões têm aspecto nodular e proliferativo e surgem, principalmente, nas regiões sem penas do corpo da ave: pálpebras, na base do bico, narinas e membros pélvicos ${ }^{8}$. Vargas et al. ${ }^{9}$ afirmaram que a localização comum das lesões em regiões sem penas é um fator que parece estar associado aos locais preferenciais de picadas de alguns artrópodes transmissores do vírus.

Segundo Mohan \& Fernandez ${ }^{4}$, os mosquitos são considerados importantes vetores para a propagação do vírus da bouba aviária. A transmissão se dá quando os mosquitos se alimentam de um pássaro infectado ou lesão contaminada e, em seguida, alimentam-se de aves saudáveis, transmitindo, assim, o vírus. A transmissão do vírus por ácaros, aerossóis, contato direto entre animais ou a ingestão de água e alimentos contaminados também são importantes formas de propagação da doença ${ }^{10}$.

$\mathrm{O}$ presente trabalho teve por objetivo reportar o primeiro caso de infecção por AVP em ave selvagem no Estado do Pará, Brasil, e ressaltar uma forma incomum de ocorrência das lesões pelo seu aspecto tumoral e a localização pouco usual.

\section{MATERIAL E MÉTODOS}

Uma ave anseriforme da família Anatidae e espécie Dendrocygna autumnalis, adulta e de sexo indeterminado, foi apreendida pelo Instituto Brasileiro do Meio Ambiente e dos Recursos Naturais Renováveis - IBAMA e encaminhada ao setor de reabilitação de aves silvestres do Parque Zoobotânico Mangal das Garças, localizado no município de Belém, Pará. A ave passou por procedimento clínico, onde se verificou a presença de dois grandes nódulos cutâneos. Optou-se pela remoção cirúrgica das neoformações com o animal submetido à anestesia utilizando xilazina IM 0,5 $\mathrm{mg} / \mathrm{kg}+$ ketamina IM $10 \mathrm{mg} / \mathrm{kg}$. Posteriormente, amostras com espessura de 0,5 $\mathrm{cm}$ das lesões foram coletadas e fixadas em formol tamponado a $10 \%$, e submetidas ao processamento histológico de rotina com a desidratação das amostras em concentrações crescentes de etanol $(70 \%, 80 \%, 95 \%$ e absoluto), clarificadas em xilol e embebidas e inclusas em Paraplast ${ }^{\circledR}$. Na sequência, foram obtidos cortes de $5 \mu \mathrm{m}$ de espessura, corados pela hematoxilina e eosina (HE) e montados com Entellan ${ }^{\circledR}$ para análise histopatológica e realização de fotomicrografias sob microscopia óptica, nos aumentos de 10, 20 e 40×.

\section{RESULTADOS E DISCUSSÃO}

O animal apresentava dois grandes nódulos, de aspecto tumoral, localizados na região proximal da articulação carpo-rádio-ulnar esquerda (Figura 1A), que mediam 4,2 x $3,8 \mathrm{~cm} \mathrm{e}$ $2,8 \times 2,2 \mathrm{~cm}$ de comprimento e largura, respectivamente. As formações apresentavam depressão na superfície dorsal e crosta úmida escura aderente (Figura 1B).

De acordo com os achados macro e microscópicos, a etiologia das lesões cutâneas de aspecto tumoral foi associada à infecção por AVP. Similar ao presente relato, Morton \& Dieterich ${ }^{11}$ diagnosticaram um caso de bouba em outra espécie de anseriforme (Anas crecca carolinensis) no Estado americano do Alasca.

Tageldin et al. ${ }^{12}$ relataram lesões por AVP de aspecto tumorais em dois espécimes de Streptopelia senegalensis, que mediram, respectivamente, $1,1 \times 0,6 \mathrm{~cm}$ (localizada dedo do pé esquerdo) e $1,2 \times 0,8 \mathrm{~cm}$ (na extremidade da asa direita). Mohan \& Fernande $z^{4}$ observaram, em pombos, múltiplos nódulos de 0,5 a $1 \mathrm{~cm}$ de diâmetro, já Morton \& Dieterich ${ }^{11}$, em 
anseriforme, (Anas crecca carolinensis) uma massa nodular, firme, de coloração escura, de 1,1 $\mathrm{cm} \times 1,3 \mathrm{~cm}$. Em flamingos jovens, as lesões tumorais associadas à infecção poxviral se apresentaram como nódulos com cerca de 3,5 - 6,0 $\mathrm{cm}$ de diâmetro, identificadas principalmente na região da cabeça das aves ${ }^{13}$.

$\mathrm{Na}$ análise histopatológica, os nódulos demonstraram crescimento epiteliomatoso dérmico com revestimento epidérmico e marginalização do derma papilar (Figura 1C). Observaram-se expressiva acantose e hiperqueratose e várias células com espongiose, resultados similares aos descritos por Arai et al. ${ }^{13}$ em flamingos jovens no Chile, bem como em um espécime de coruja no Estado do Rio Grande do $\mathrm{Sul}^{9}$. Adicionalmente, abundantes mantos de queratina, entre lóbulos de tecido epitelial hiperplásico (alguns situados centralmente aos lóbulos) foram encontrados. O estroma interlobular mostrou-se discreto. Similarmente ao presente caso, Mohan \& Fernandez ${ }^{4}$ descreveram, na bouba, espongiose de queratinócitos e crostas queratináceas.

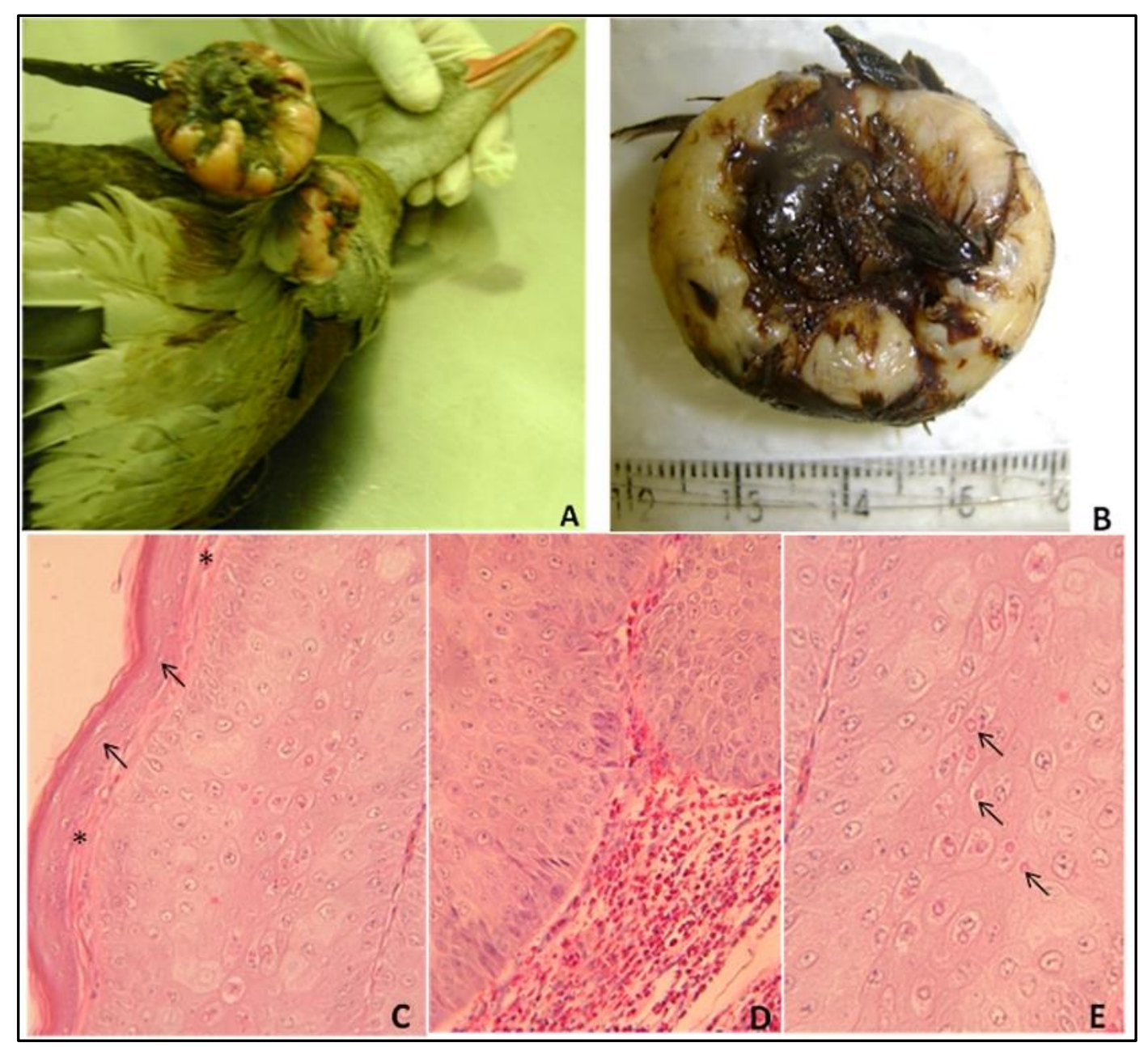

Figura 1A: Dois grandes nódulos de aspecto tumoral localizados na região proximal da articulação carporádio-ulnar esquerda. 1B: Nódulo com depressão na superfície dorsal e crosta úmida aderente, medindo 4,2 $\mathrm{x}$ 3,8 cm. 1C: Crescimento epiteliomatoso dérmico, com revestimento epidérmico (setas) e marginalização do derma papilar(*) H\&E. 200x. 1D: Notável infiltrado de eosinófilos no estroma conjuntivo do crescimento epiteliomatoso. H\&E. 200x. 1E: Corpúsculos de inclusão intra-citoplasmáticos eosinofílicos (setas) em queratinócitos. H\&E 400x. 
Nas margens do crescimento epiteliomatoso, o estroma conjuntivo apresentou destacado infiltrado de eosinófilos (Figura 1D). O infiltrado associado à infecção pelo AVP é composto predominantemente por heterófilos e linfócitos ${ }^{12}$ na região dermal, já que as lesões proliferativas tendem a permanecer restritas à epiderme. O diagnóstico de bouba aviária em $D$. autumnalis foi estabelecido a partir da presença de grandes corpúsculos de inclusão intracitoplasmáticos eosinofílicos (Corpúsculo de Bollinger) nas células epiteliais (Figura 1E), referido como sinal patognomônico da enfermidade ${ }^{4}, 12,14$. Esses corpúsculos foram maiores e mais numerosos nas células mais estratificadas em relação ao estrato germinativo, aspecto também observado por Morton $\&$ Dieterich $^{11} \mathrm{em}$ anseriforme (A.c. carolinensis). Salienta-se que na forma cutânea da doença, as lesões podem adquirir aspecto tumoral, fato que pode estar associado à cepa viral em circulação na região, modo de transmissão e susceptibilidade da espécie aviária em questão.

A lesão cutânea tumoral apresentada no presente relato representou um processo hiperplásico; no entanto, Gortázar et al. ${ }^{15}$ reportaram, na Espanha, um caso de carcinoma espinocelular em Alectoris rufa associado à infecção pelo AVP. Esses autores observaram, histologicamente, inclusões intra-citoplasmática nas celulas epiteliais tumorais e, por microscopia eletrônica, detectaram partículas virais em algumas dessas células. Os autores consideraram, ainda, a possibilidade de uma forma latente ou crônica do poxvírus na patogênese da lesão, hipótese também sugerida por Fallavena et al. ${ }^{16}$.

De modo similar, Pesaro et al. ${ }^{17}$ identificaram lesões sugestivas de infecção poxviral (corpúsculos de Bollinger) no tecido neoplásico de um ceratoacantoma localizado na superfície plantar do um pelicano (Pelecanus rufences), sugerindo, assim, uma possível participação do AVP na etiologia de processos neoplásicos cutâneos em aves silvestres.

A região proximal da articulação carporádio-ulnar esquerda não caracteriza uma localização usual para os nódulos da bouba em D. Autumnalis, visto que as lesões ocorrem, principalmente, em áreas desprovidas de pena como na crista, pálpebras e membros posteriores ${ }^{8}$. Catroxo et al..$^{5}$ relataram serem os pés o principal local de lesões poxvirais em 40 passeriformes (100\%) no Estado de São Paulo. Tageldin et al. ${ }^{12}$ descreveram lesões no dedo da perna esquerda e extremidade da asa direita, e consideraram tais localizações incomuns para a infecção pelo poxvírus em aves. Back et al. ${ }^{14}$ observaram lesões de bouba em frangos de corte manifestando-se em partes do corpo cobertas de penas, principalmente na área dorsal e parte externa da coxa. Na mesma espécie, Sentíes-Cué et al. ${ }^{18}$ reportaram lesões no quadril, abdômen e área lateral do pescoço.

Em virtude da ulceração epitelial em uma região recoberta por penas, como os descritos no presente relato, associada à infecção bacteriana secundária, podem ser identificados processos de foliculite supurativa nas regiões circunjacentes ${ }^{19}, 20$. A superfice epidérmica das lesões pode apresentar necrose e ulceração e deposição de material eosinofílico, amorfo ${ }^{4}$; entretanto, a hiperplasia epitelial, o aumento no tamanho das células (balonese), associados à formação dos corpúsculos de Bollinger e às modificações inflamatórias, constituem os principais achados microscópicos de infecção na bouba aviária, tanto nas formas cutânea como diftérica ${ }^{6}$.

\section{CONCLUSÃO}

Observaram-se neste trabalho lesões com aspecto tumoral e achados histopatológicos compatíveis com infecção por Avipoxvirus em um espécime de Dendrocygna autumnalis, indicando a circulação do AVP em espécie silvestre no Estado do Pará.

\section{REFERÊNCIAS}

1. Eo KY, Kim YH, Cho KH, Jang JS, Kim TH, Kwak D, Kwon OD. Infection of avian pox virus in oriental turtledoves. Pakistan Veterinary Journal, 2011;31(4):354-356.

2. Moço HF, Dias LC, Andolfato LHM, Alves ML, Bronzatto A, Raya DA. Bouba Aviária. Revista Científica Eletrônica de Medicina Veterinária Veterinária, 2008;6(11):1-5.

3. Bolte AL, Meurer J, Kaleta EF. Avian host spectrum of avipoxviruses. Avian Pathology, 1999;28(5):415-432.

4. Mohan M, Fernandez TF. A case report of Pigeon Pox Histopathologic Diagnosis. Veterinary World, 2008;1(4):117-118.

5. Catroxo MHB, Pongiluppi T, Melo NA, Milanelo L, Petrella S, Martins AMCPF, Rebouças MM. Identification of Poxvirus under transmission electron microscopy during outbreak period in wild birds, in São Paulo, Brazil. International Journal of Morphology, 2009;27(2):577-585.

6. Tsai SS, Chang TC, Yang SF, Chi YC, Cher RS, Chien MS, Itakura C. Unusual lesions associated with avian poxvirus infection in rosy-faced lovebirds (Agapornis roseicollis). Avian Pathology, 1997;26(1):75-82.

7. Mete A, Borst GHA, Dorrestein GM. Atypical poxvirus lesions in two Galapagos doves (Nesopelia $g$. galapagoensis). Avian Pathology, 2001;30(1):159-162. 
8. Smits JE, Tella JL, Carrete M, Serrano D, Lopez G. An Epizootic of Avian Pox in Endemic Short-toed Larks (Calandrella rufescens) and Berthelot's Pipits (Anthus berthelotti) in the Canary Islands, Spain. Veterinary Pathology, 2005;42(1):59-65.

9. Vargas GD, Albano AP, Fischer G, Hübner S, Sallis, SE, Nunes, CF, Raffi MB, Soares MP. Avian pox virus infection in a common barn owl (Tyto alba) in Southern Brazil. Pesquisa Veterinária Brasileira, 2011;31(7):620622.

10. Pledger, A. Avian pox virus infection in a mourning dove. Canadian Veterinary Journal, 2005;46(12):11431145 .

11. Morton JK, Dieterich RA. Avian pox infection in an American green-winged teal (Anas crecca carolinensis) in Alaska. Journal of Wildlife Diseases, 1979;15(3):451-453.

12. Tageldin MH, Johnson EH, Al-Amri IS, Ali Aisha A. Cutaneous tumor-like lesions associated with poxvirus infection in laughing doves. Journal of Avian Medicine and Surgery, 2006;20(2):94-96.

13. Arai S, Arai C, Fujimaki M, Iwamoto Y, Kawarada M, Saito Y, Nomura Y, Suzuki T. Cutaneous tumour-like lesions due to Poxvirus infection in Chilean flamingos. Journal of Comparative Pathology, 1991;104(4):439-441.

14. Back A, Soncini RA, Ruthes O, Madureira JS, Flores R. An atypical fowl pox outbreak in broilers in Southern
Brazil. Avian Diseases, 1995;39(4):902-906.

15. Gortázar C, Millán J, Höfle U, Buenestado FJ, Villafuerte R, Kaleta EF. Pathology of avian pox in wild Red-Legged Partridges (Alectoris rufa) in Spain. Annals of the New York Academy of Sciences,2002;969(1):354357.

16. Fallavena LCB, Canal CW, Salle CTP, Moraes HLS, Rocha SLS, Pereira RA, Da Silva AB. Presence of avipoxvirus DNA in avian dermal squamous cell carcinoma. Avian Pathology, 2002;31(3):241-246.

17. Pesaro S, Biancani B, Fabbrizi G, Rossi G. Squamous cell carcinoma with presence of poxviruslike inclusions in the foot of a pink-backed pelican (Pelecanus rufescens). Avian Pathology, 2009;38(3):229-231.

18. Sentíes-Cué CG, Charlton BR, Woolcock P, Bickford AA, Cooper G, Bland M. Atypical distribution of fowl pox lesions in broilers. Avian Diseases, 2010;54(4):13161318.

19. Wingate DB, Barker IK, King NW. Pox virus infection of the white-tailed tropicbird (Phaethon lepturus) in Bermuda. Journal of Wildlife Diseases, 1980;16(4):619-622.

20. Krone O, Essbauer S, Wibbelt G, Isa G, Rudolph M, Gough RE. Avipoxvirus infection in Peregrine falcons (Falco peregrinus) from a reintroduction programme in Germany. Veterinary Record, 2004;154(4):110-113. 